\title{
NUMBER OF QUESTIONS FOR CREATING ONLINE QUIZZES
}

\author{
Tanya Pehlivanova ${ }^{1}$ \& Kamen Kanchev ${ }^{2}$ \\ ${ }^{1}$ Faculty of Technics and Technologies of Yambol, \\ Trakia University of Stara Zagora, Bulgaria \\ Graf Ignatiev 38, 8602 Yambol, Bulgaria \\ e-mail: tanya.pehlivanova@trakia-uni.bg \\ ${ }^{2}$ Faculty of Mathematics and Informatics, Sofia University, Bulgaria \\ James Bourchier 5, 1164 Sofia, Bulgaria \\ e-mail: kamentk@abv.bg
}

\begin{abstract}
This article presents results of a study of the opinion of former and current students on issues related to the evaluation with e-tests. The experience of lecturers conducting assessment in technical and computer disciplines with tests in e-learning environment Moodle from Faculty of Technics and Technologies of Yambol is also analyzed. Analyzes and research carried out show that the progress of the technologies and their entry into education leads to one negative effect. Some of the students use digital technologies to access exam test questions and learn only these questions rather than the teaching content. Conclusions are made on the minimum number of questions from which the tests should be formed. Measures have been proposed for easy and fast automated raising of the total number of questions in the bank by developing Plugins in Moodle, allowing the creation of new types of test questions.
\end{abstract}

Keywords: e-learning, e-tests, Muddle, testing.

\section{INTRODUCTION}

In the last years more are spoken of this, and hardly anyone doubts that it is imperative to use ICT-based innovative educational technologies and adapt the education system to the digital generation. Modern generation has a completely different way of thinking and learning. Often, in terms of new technologies, they overtake the lecturers, most of whom were born and even completed their education before the computers entered our lives [4].

One of the most accessible and rapidly entering in the higher education system contemporary educational practices are the electronic forms of distance learning. All universities now have an e-learning environment (platform). Thus, students receive access to electronic resources from anywhere, anytime.

A major element of e-learning is the assessment of learner knowledge using electronic tests. As the results of the tests serve to make certain management decisions related to the evaluation and the passing to the next stage of the training, then the reliability of the evaluation obtained should be large [2].

This article presents results of a study of the opinion of former and current students on issues related to the evaluation with electronic tests. The experience of lecturers conducting assessment in technical and computer disciplines with tests in e-learning environment Moodle from Faculty of Technics and Technologies of Yambol is also analysed. The analyses and research carried out show that the progress of the technologies and their usage in education leads to one negative effect. Some of the students use digital technologies to access exam test questions. This enables them if the tests contain small number of questions and the same questions each year to learn only those questions rather than the teaching content.

IRTIIE Vol. 7, No. 1, 2019 ISSN 1314-8788 (print), ISSN 1314-8796 (online), doi: 10.15547/artte.2019.01.007 


\section{ART'TE

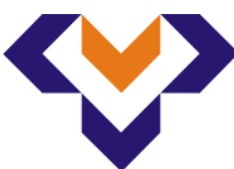

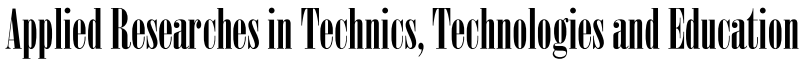 \\ Journal of the Faculty of Technics and Technologies, Trakia University https://sites.google.com/a/trakia-uni.bg/artte/}

The aim of the study is to improve the quality of assessment by e-tests. Conclusions are made on the minimum number of questions in the bank with questions from which the tests are formed. Measures are proposed to quickly and easily increase the total number of questions by developing plugins for Moodle, allowing the creation of new types of test questions.

\section{METHODS}

The conclusions are based on a survey of 54 former and current students who graduated or trained in technical, computer, economic and other specialties in different universities in the cities of Sofia, Yambol, Plovdiv and others. The age of the respondents is up to 40 years because the questions are mostly related to digital training methods, and it is supposed that the older ones have completed their education before their wide entry into practice.

The results of the tests conducted in Faculty of Technics and Technologies of Yambol on the subjects "Lighting and installation equipment", "Design of lighting systems", "CAD systems", "Microprocessor engineering", etc. are also analyzed.

\section{RESULTS}

Assessment with electronic tests has many advantages, such as increased reliability, avoiding subjectivism, time savings, interactivity, adaptability, and more. It also has some major disadvantages such as dependence on network security and stability, use of unallowed help materials, possibility of manipulation and others. When correctly using the resources of e-learning systems these disadvantages are subject to control [1].

Lecturers can use different options for electronic tests. The easiest option is to ask the same questions to all tested students. This, however, is not applicable to assessing a large number of students because it is very difficult to provide a computer for all at the same time. The lecturers have no way of preventing the "leak" of the questions, and thus the students who are tested later are significantly more successful than the first one to take the test. Therefore, tests in which test variants are randomly generated from a bank with test questions grouped by topic, difficulty, or other criteria are more often applied. If the total number of questions in the bank is small, again there is a risk of prior learning these questions. Especially if the same questions are used for more than one year, as is the practice in many of the universities in Bulgaria.

An analysis of the results of the assessment of students in technical and computer disciplines with tests in the e-learning environment Moodle in Faculty of Engineering and Technologies - Yambol is made. For example: For four years (from 2015 to 2018) when tested with the same questions bank in the discipline "Lighting and installation equipment", the average student success rate in a group increased from 3.98 to 4.48 . For the same students it cannot be said that they have a higher average success in other disciplines where the evaluation is not electronic.

Moreover, in enriching tests with new questions in the bank in the first year, the number of wrong answers for them is the largest and gradually decreasing.

This analysis speaks of a "leak" of the questions and that lecturers should not underestimate fraud prevention measures. This is confirmed and by the study conducted. $65.4 \%$ of respondents acknowledge that they have used unauthorized help materials based on modern digital technologies at least once during their training (Figure 1). There is a tendency with age reduction this percentage to be increased. In computer and technical specialties this percentage is higher, but the use of paper materials is reduced. It cannot be said that students with lower average success transcribe more.

IRTIIE Vol. 7, No. 1, 2019 ISSN 1314-8788 (print), ISSN 1314-8796 (online), doi: 10.15547/artte.2019.01.007 


\section{IRTTE

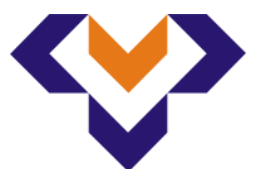 \\ Ipplied Researl'hes in Technics, Technologies ind Bductition Journal of the Faculty of Technics and Technologies, Trakia University https://sites.google.com/a/trakia-uni.bg/artte/}

These percentages refer to all evaluation methods. The results are also very similar to the evaluation with electronic tests. The distribution of responses, regardless of age, is shown in Figure 2.

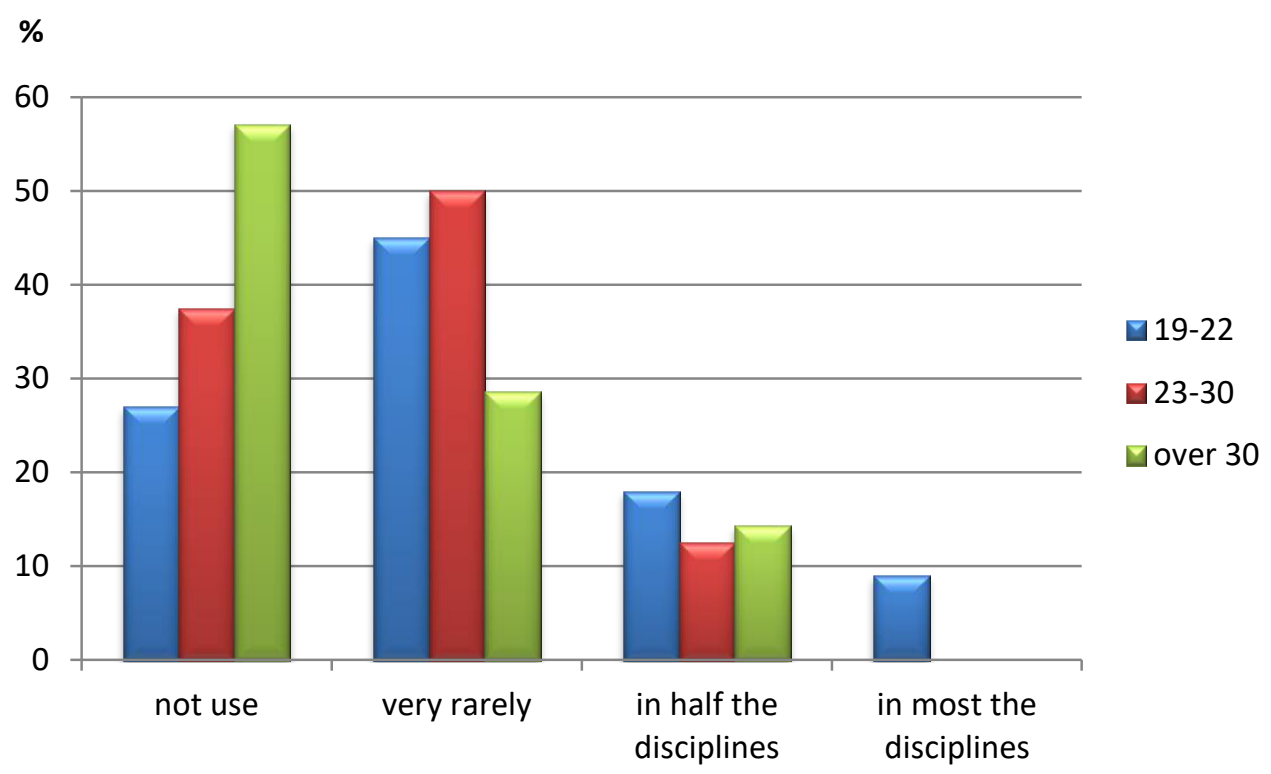

Figure 1. Frequency of use of unauthorized electronic help materials by age

Technological development assist training, but at the same time creates unlimited opportunities for abuse. In spite of the efforts of the evaluators after evaluation with the same questions several times, they become available to students. To the question "In the preparation for electronic tests, did you have a complete or partial set of questions from which the test is formed (without this being allowed by the lecturer)?", $40 \%$ of the respondents answered positively and $16 \%$ of the respondents had materials in half or most disciplines.

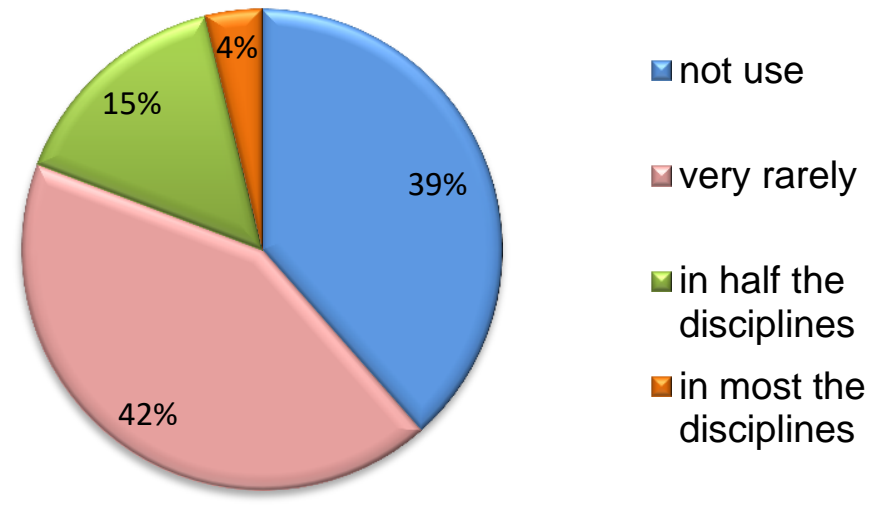

Figure 2. Frequency of using unauthorized help materials in evaluating with electronic tests

$53.8 \%$ of surveyed students rated electronic test as the easiest way of testing. The others also think that it is one of the easiest. All respondents consider it more difficult when the testing is done by writing questions, with or without oral discussion, with practical tasks and projects, even with paper tests. The reason for this lies in the possibility of guessing the IRTIIE Vol. 7, No. 1, 2019 ISSN 1314-8788 (print), ISSN 1314-8796 (online), doi: 10.15547/artte.2019.01.007 


\section{IRTITE

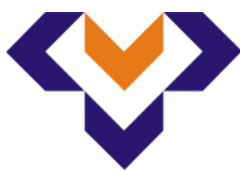 \\ Ipplied Resseirlohes in Technics, Technologies ind Bductition \\ Journal of the Faculty of Technics and Technologies, Trakia University https://sites.google.com/a/trakia-uni.bg/artte/}

correct answers and in the possibility of using unauthorized electronic help materials.

Respondents were asked to put themselves in a situation where they solved an electronic test consisting of randomly selected questions from a bank with previously known questions. They answered how many questions must include the bank so that they will prefer to study the theory (why and how to get the answer to the question) rather than memorizing the answers to the questions or looking for a way to transcribtion the answers to the exam. $42.3 \%$ said that regardless of the number of questions they would prefer to study the theory rather than the correct answers. 19.23\%, however, would study the theory and would not attempt to use unallowed materials or remember the correct answers if the questions are more than 600 and $15.38 \%$ - if they are more than 1000. The results obtained are shown in Figure 3.

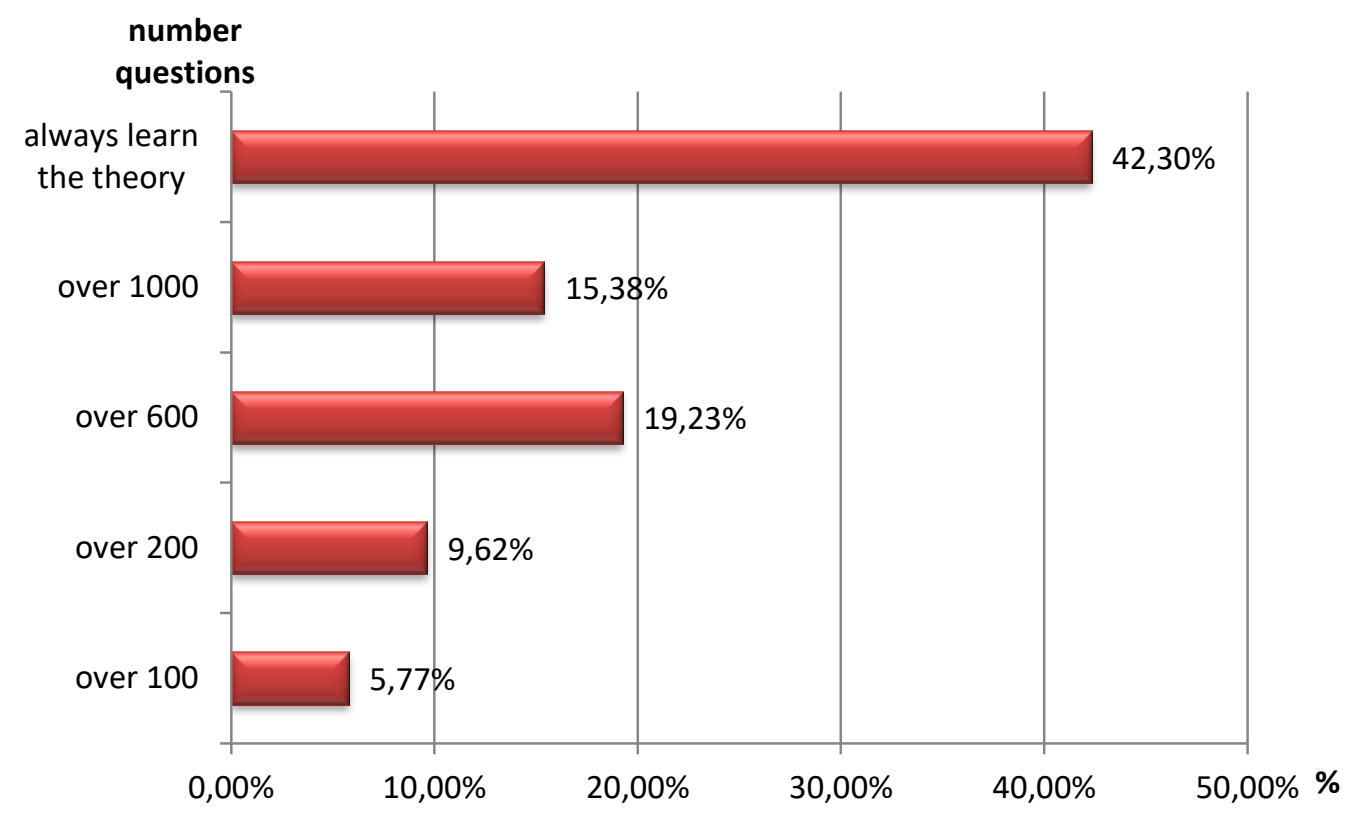

Figure 3. Number of questions in the question bank that students are stimulated to learn the learning content

The creation such questions bank requires serious time and effort on the part of the examiners.

The number of questions in the bank can be increased automatically by developing plugins for creation of new types of questions in the Moodle e-learning system. Thus, the negative aspects of the assessment with electronic tests can be minimized.

The proposed method is based on the fact that during the exam, some students try to mechanically recognize the questions by keyword used in both the formulation of the questions and the formulation of the answers. With a bank of several hundred questions, recognition can hardly be done from paper help materials or photographs. Typically, computer files are used in which all questions are saved. Usually they sorted in alphabetical order and the question is easily reached by the first words. Also it is possible to find it using the "find" command available in all modern text and data editors.

Recognition of a question by incompetent students can be significantly hampered if it appears with a different formulation every time the test is started.

This method is applicable to questions of type: Multiple Choice; Short Answer; Comparison; Numeric; Computing; Truth/ False.

Adding a different wording to the answers to the multiple choice questions, the variants of the question can become much more.

IRTIIE Vol. 7, No. 1, 2019 ISSN 1314-8788 (print), ISSN 1314-8796 (online), doi: 10.15547/artte.2019.01.007 


\section{IPITIP Journal of the Faculty of Technics and Technologies, Trakia University https://sites.google.com/a/trakia-uni.bg/artte/}

\section{EXAMPLES}

The texts of the following "Multiple Choice Questions" can be formulated in several ways that are equally true, but they sound completely different:

\subsection{Example 1}

Question 1:

1. For the scheme of the figure, the first Kirchhoff law is recorded as follows:

2. Prescribe the correct equation for the given scheme.

3. Kirchhoff's first law for the scheme is:

4. The right equation for the given scheme is:

5. The scheme of Figure 4 is given. Mark the correct equation for it.

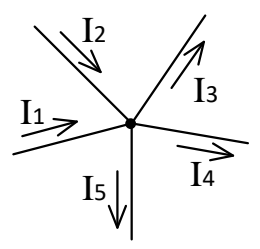

Figure 4. The first Kirchhoff law

Answers to Question 1:

a) $\mathrm{I}_{1}+\mathrm{I}_{2}+\mathrm{I}_{3}+\mathrm{I}_{4}+\mathrm{I}_{5}=0$;

b) $\mathrm{I}_{1}+\mathrm{I}_{2}+\mathrm{I}_{3}=\mathrm{I}_{4}+\mathrm{I}_{5}$;

c) $\mathrm{I}_{1}+\mathrm{I}_{2}=\mathrm{I}_{3}+\mathrm{I}_{4}+\mathrm{I}_{5}$.

The correct answer is $\mathrm{c}$ ). It can also be recorded in 2 ways without changing the quality of the test:

$I_{1}+I_{2}=I_{3}+I_{4}+I_{5}$ and

$I_{1}+I_{2}-I_{3}-I_{4}-I_{5}=0$

Thus, with various combinations, are received 10 different questions.

\subsection{Example 2}

\section{Question 2:}

Indicate the correct statement.

Specify the option is correct

Which of the following statements about single-phase transformers is true?

Select the one that is true

For single-phase transformers it is true that:

Answers to Question 2:

a) The single phase transformer has six winding.

b) The single phase transformer serves to reduce or increase the voltage supplied to the primary winding.

c) The single phase transformer can operate at constant and alternating current.

The correct answer b) can also be expressed as follows: "The single phase transformer serves to change the value of the voltage supplied to the primary winding." Another reliable answer is possible. For example: "The single-phase transformer can only work with alternating current." Or "One-phase transformer has two windings" and so on.

Thus, with various combinations, are received 20 different questions.

IRTIIE Vol. 7, No. 1, 2019 ISSN 1314-8788 (print), ISSN 1314-8796 (online), doi: 10.15547/artte.2019.01.007 


\section{ARTIIE

This is not equal to creating two or more different questions. If these different variants are introduced to the bank as different records, then when creating tests by generating random questions from a category, there is an opportunity a single student receive two practically identical questions in a test. This disadvantage is avoided by applying the proposed plugin in Moodle [3].

Another possibility to increase the number of questions is doubling the truth/false questions. This can be done by giving in the formulation of the question of two alternative statements (opposing statements, one of which is true and the other is false).

Currently exist plugins for many variants of the same question in the computing questions (Computing, Simple Computing and Closed Computing), where it is possible to randomly generate a number of combinations of values within a predefined range.

\section{CONCLUSIONS}

- The study conducted among students demonstrates that a large percentage of them use unallowed help materials in evaluation by electronic tests. $40 \%$ of respondents, in preparation for electronic tests at least once had a complete or partial set of questions from which the test is formed (without this being allowed by the lecturer)

- With a total number of questions in the bank from which the tests are formed, greater than $600,34.6 \%$ of the respondents will be encouraged to learn the learning content and not to attempt to use unallowed help materials or to memorize the correct answers. For a total number greater than 1000, this applies to all tested.

- An automated method has been proposed to increase the number of questions in the bank by creating plugins in the Moodle e-learning system.

\section{REFERENCES}

[1] Ivanov I. (2014). Problems of Online Assessment. Proceedings of the Fifth National Conference on E-Learning in Higher Schools, Rousse, (2014), pp. 295-301.

[2] Petrova M. (2007). Tests as a tool for improving the quality of distance learning, Pedagogical Almanac Magazine, Vol. 15, No. 1, (2007), pp. 245-264.

[3] Pehlivanova T. \&, Kanchev K. (2018), Plugin for creating a new type of questions in Moodle, Proceedings of the International Conference on Technics, Technologies and Education ICTTE 2018, Yambol, October 18-19, (2018).

[4] Smirarov A., Ivanova A., Atanasov V., Stoykova V. \& others. The Role of Innovative Educational Technologies and Didactic Models for Adapting the Educational System to the Digital Generation. Rousse University Publishing House, Rousse, (2017). 